\title{
A práxis da enfermeira e a integralidade no cuidado
}

Recebido em: 01/03/2011

Aceito em: 14/04/2011

\author{
Francine Lima Gelbcke ${ }^{1}$ \\ Kenya Schmidt Reibnitz ${ }^{2}$ \\ Marta Lenise do Prado ${ }^{3}$ \\ Margarete Maria de Lima ${ }^{4}$ \\ Daiana Kloh ${ }^{5}$
}

O presente trabalho visa a refletir sobre a articulação entre o conhecimento e a ação numa perspectiva de uma práxis que permita à enfermagem um trabalho interdisciplinar, na direção da integralidade do cuidado. Isso se coloca como uma realidade inevitável nos dias de hoje. Discorre-se sobre o papel da enfermeira nesse contexto, um papel que pressupõe refletir sobre diferentes aspectos que envolvem a enfermagem e a integralidade do cuidado, nas diferentes dimensões de seu fazer: educar, gerenciar e cuidar.

Descritores: Cuidado, Educação, Enfermagem, Prática Profissional.

\section{A practice nurse and completeness of care}

The present work aims to ponder on the relationship between knowledge and action from the perspective of a nursing practice that allows an interdisciplinary work towards comprehensive care. Nowadays this is an inevitable reality. Therefore, it is worthwhile to dwell a little on the role of the nurse in this context, a role that involves reflecting on different aspects of nursing and comprehensive care, the different dimensions of their making: to educate, manage and care.

Descriptors: Care, Education, Nursing, Professional Practice.

\section{La praxis de la enfermería y la integralidad en el cuidado}

El presente trabajo tiene como objetivo reflexionar sobre la relación entre conocimiento y acción desde la perspectiva de una práctica de enfermería, que permite un trabajo interdisciplinario en la atención integral. Este surge como una realidad inevitable en la actualidad. Reflexiona acerca del papel de la enfermera en este contexto, un papel que implica la reflexión sobre diferentes aspectos de la enfermería y la integralidad del cuidado en salud, las diferentes dimensiones de su hacer: educar, administrar y cuidado.

Descriptores: Cuidado, Educación, Enfermería, Práctica Profesional.

\section{INTRODUÇÃO}

\section{A integralidade do cuidado: conhecer para agir}

omo podemos definir integralidade do cuidado? Que concepções permeiam esses termos? Como temos trabalhado a integralidade em nosso cotidiano? A enfermagem tem buscado trabalhar com a integralidade? Muitos são os questionamentos acerca desse tema, e refletiremos sobre alguns deles, já que essa é uma discussão que ainda está começando em nossa profissão.

$\mathrm{E}$, para iniciarmos nossa reflexão, nós nos apoiamos em Sawaia(1) ao discutir acerca da "falsa cisão retalhadora do homem", quando ele afirma que há necessidade de buscar a complementaridade entre o uno e o múltiplo, o simples e o complexo, a objetividade e a subjetividade, o particular e o universal, a mente e o corpo, o indivíduo e o coletivo, ou seja, entre tantas dicotomias que foram sendo estabelecidas ao longo da história do conhecimento ocidental.

E por que pensar nessas complementaridades? Porque nós, seres humanos, somos assim, temos presentes em nós tais dicotomias, as quais precisam ser consideradas; não podemos levar em conta um lado sem o outro, sem as relações de complementaridade, quando cuidamos de forma integral. Desse modo, "afeto, identidade, emoção e necessidade são questões sociopolíticas tanto quanto instituição, classe social, relações de poder e trabalho são questões subjetivas; são passagens de uma instância a outra, em que estão sempre em confronto: o uno e o múltiplo. Quando esse confronto é bloqueado, cessa

1 Enfermeira. Doutora em Enfermagem. Professora Adjunta do Departamento de Enfermagem e do Programa de Pós-Graduação de Enfermagem da UFSC. Diretora de Enfermagem do Hospital Universitário Prof. Polydoro Ernani de São Thiago. E-mail: fgelbcke@nfr.ufsc.br.

2 Enfermeira. Doutora em Enfermagem. Professora Titular do Departamento de Enfermagem e do Programa de Pós-Graduação de Enfermagem da UFSC. Diretora do Centro de Ciências da Saúde da UFSC. Membro do Grupo de Pesquisa Eden. Florianópolis, Santa Catarina.

3 Enfermeira. Doutora em Enfermagem. Professora Adjunta do Departamento de Enfermagem e do Programa de Pós-Graduação de Enfermagem da UFSC. Membro do Grupo de Pesquisa Eden. Florianópolis, Santa Catarina.

4 Enfermeira. Mestre em Enfermagem. Doutoranda do Programa de Pós-Graduação em Enfermagem (PEN) da UFSC. Bolsista CNPq-Doutorado. Membro do Grupo de Pesquisa Eden. Florianópolis, Santa Catarina.

5 Enfermeira. Mestranda do Programa de Pós-Graduação em Enfermagem (PEN) da UFSC. Bolsista CNPq-Mestrado. Membro do Grupo de Pesquisa Eden. Florianópolis, Santa Catarina. 
o movimento e a vivacidade do homem, dos grupos e da sociedade, que se tornam caricaturas de si mesmos"(1:101).

Nas instituições, na vida cotidiana, as relações se estabelecem por meio de funções preestabelecidas, em que ocorre o desempenho automático dessas funções, impostas por rotinas e normas, impedindo que os trabalhadores participem por inteiro, com seus sentimentos, ideias e paixões. No entanto, esse cotidiano também pode ser o espaço de se apreender o mundo, objetivando-o, dentro das possibilidades oferecidas por este mundo.

É para entender o cuidado e sua integralidade que não podemos pensar no ser humano de forma preconceituosa, individualista, objetiva, dicotômica, mas sim de forma integral, suplantando as dicotomias presentes no cotidiano, associando objetividade e subjetividade, ou seja, entendendo esse ser humano com suas emoções, sentimentos, paixões e sensações, como um ser subjetivo, que tem manifestações objetivas, como um ser por inteiro.

E de que integralidade estamos falando?

$\mathrm{Na}$ enfermagem, desde o advento das teorias de enfermagem, na década de 1970, tem-se discutido o ser humano como um ser holístico. No entanto, nosso fazer permanece permeado por dicotomias, privilegiando o corpo biológico em detrimento do social, descartando-se o subjetivo. O fazer imediato é pautado por regras, normas, prescrições generalizantes, ou seja, trata-se de um cuidado dicotomizado, em que parte da equipe pensa e parte realiza o que foi prescrito. Será esse nosso cuidado holístico e integral?

Para viabilizar a integralidade do cuidado, há que estabelecer mudanças no cotidiano das instituições de saúde, buscando a responsabilização no cuidado ao usuário, o real encontro entre quem cuida e quem é cuidado, quer dizer, estabelecendo um vínculo, valorizando o que Merhy ${ }^{(2)}$ chama de tecnologias leves, como as que envolvem a relação com o outro, um cuidado que tenha como princípio as necessidades singulares dos sujeitos.

Essa integralidade suplantaria o modo como hoje se organiza a produção de atos de saúde, centrados em procedimentos, para atos centralizadosnasnecessidadesdossujeitosdocuidado,envolvendo para isso a articulação dos diferentes atores que produzem tal cuidado. A ideia é possibilitar não só a multidisciplinaridade, mas a interdisciplinaridade, em que as expressões individuais e coletivas sejam possíveis, se reconheçam e se respeitem a multiplicidade e a diversidade entre os sujeitos.

Há que se pensar que a integralidade do cuidado implica em movimento, em processo de interação, em idealizar o projeto de cuidado e responsabilizar-se pelo cuidado. Nesse sentido, o atendimento integral requer a superação da estrutura organizacional hierarquizada e regionalizada da assistência de saúde, exigindo o compromisso com o contínuo aprendizado e com a prática multiprofissional ${ }^{(3)}$. Por isso, é preciso considerar a necessidade de reorganizar os serviços de saúde, e cabe à enfermagem refletir acerca desse significado, tanto no cotidiano das instituições de saúde quanto das instituições formadoras.
Repensar a prática da enfermagem e seu papel no contexto das instituições de saúde, na abertura de espaços para o diálogo, tanto com os profissionais quanto com os sujeitos do cuidado, se fazem necessários. Para tanto, mais do que discutir, há que se transformar a prática, nosso fazer, que ainda se pauta, em muito, na fragmentação do sujeito, do conhecimento e do cuidado.

\section{A práxis da enfermeira: articulando o cuidar, o gerenciar e o educar}

Cuidar, gerenciar e educar compõem o processo de trabalho da enfermagem, tendo objetivos específicos, de acordo com cada processo particular, visando ao bem-estar do ser humano, objeto de seu processo de trabalho. Esses diferentes processos definem o papel que deve ser desempenhado pela enfermeira e que precisa ser evidenciado na formação do profissional e no cotidiano de trabalho.

No entanto, em muitas situações, o gerenciar se sobrepõe ao cuidar e ao educar. Destaca-se que a formação da enfermeira privilegia a assistência direta e o gerenciamento da assistência. No entanto, o mercado de trabalho espera que a enfermeira realize o controle burocrático da instituição. Além disso, o modelo assistencial vigente opera na óptica da hegemonia médica, que acaba por subordinar as dimensões do cuidado a um papel coadjuvante e complementar ${ }^{(4)}$.

No espaço assistencial, nos diferentes cenários de atenção à saúde, é a enfermeira que articula os diversos serviços, realizando a coordenação do cuidado, desempenhando um papel "silencioso" no cotidiano de trabalho, que visa a garantir os insumos necessários a sua realização ${ }^{(5: 8)}$. Entendemos que esse trabalho silencioso, importante para a integralidade do cuidado, precisa ser realmente assumido por nós, enfermeiras, no sentido inclusive de valorizá-lo, de termos maior autonomia para realizá-lo, sem esquecer de nos instrumentalizarmos para tal. Nesse sentido, nos perguntamos: até que ponto temos discutido a integralidade do cuidado e nosso papel de gestão nesse contexto?

A enfermagem, ao refletir acerca da integralidade no cuidado, precisa discutir o que pretende, como pode participar de forma ativa, que tipo de gestão do cuidado realiza no contexto das práticas em saúde. Isso porque o modelo assistencial ainda fortemente presente em muitas instituições está pautado nos princípios da administração científica e do funcionalismo, os quais são insuficientes para abordar, "com competência, as questões da micropolítica do hospital, em particular seus mecanismos de coordenação"(6:2). Dessa forma, as enfermeiras têm papel primordial na construção de um novo modelo de gestão, que articule, de forma solidária, os diferentes trabalhos.

Salienta-se que as atividades gerenciais do enfermeiro deveriam confluir para a qualidade do cuidado, foco do processo de trabalho em enfermagem. A cisão entre a assistência e a gerência de enfermagem compromete a qualidade do cuidado e gera conflitos no trabalho do enfermeiro ${ }^{(7)}$ - conflitos esses que a maioria dos 
enfermeiros não possui capacitação formal para solucionar.

Essa lacuna na formação da enfermeira em relação às dinâmicas das relações interpessoais foi apontada em diferentes estudos $^{(8-11)}$, sendo mais um dos aspectos a ser enfrentados pelos profissionais de enfermagem que assumem o papel de gerentes nas unidades de internação hospitalares e que têm assumido com maior frequência o gerenciamento de unidades básicas de saúde e funções gerenciais nas Secretarias de Saúde. Acreditamos que tal lacuna na formação precisa ser corrigida, já que cabe à enfermeira administrar os conflitos entre a equipe de enfermagem e também entre os membros da equipe multiprofissional. Entender a dinâmica das relações interpessoais pode ser um fator minimizador de conflitos, para se estabelecer relações de trabalho mais harmônicas, e repercutindo, dessa forma, na qualidade do cuidado.

Em relação ao cuidar, outra dimensão do processo de trabalho da enfermeira, há que se perguntar que "cuidar" é esse, identificado muitas vezes não como um fazer conjunto com os trabalhadores, e sim um "auxílio para" os demais trabalhadores da equipe de enfermagem e dos outros profissionais de saúde. Que integralidade é essa, se ainda mantemos funções parcelares, mesmo com um discurso de cuidado integral, ao definirmos o que a equipe deve realizar? $\mathrm{O}$ modo de organização do trabalho da enfermagem está orientado para a prestação de um cuidado integral, que tem no sujeito cuidado o foco dessa organização?

Há uma relação direta entre controle, supervisão e poder. O tipo de controle exercido será ordenado pelo tipo de poder aplicado. O enfermeiro, ao abrir mão do poder autoritário, propicia o surgimento de um tipo de poder que desperta, liberta, une e valoriza as potencialidades do ser humano, além de fortalecer o senso de equipe ${ }^{(12)}$. Isso reforça a necessidade de a equipe de enfermagem refletir acerca da necessidade de um processo de trabalho participativo, democrático e prazeroso, que seja capaz de superar os conflitos decorrentes de relações de poder.

Nesse contexto, surge um grande paradoxo entre o mundo do trabalho e o mundo da escola. Enquanto na formação do enfermeiro há um privilégio da dimensão cuidar, por ser considerada a essência da profissão, o mundo do trabalho privilegia a dimensão gerenciar, reservando ao enfermeiro a posição de gerente do cuidado, ou, mais apropriadamente, do serviço, já que suas funções, muito frequentemente, extrapolam sua competência. Há então uma negação da função gerencial do enfermeiro como supervisão e gerenciamento do cuidado no processo de formação, e inversamente um privilégio da dimensão cuidar no mundo do trabalho. A constatação desse paradoxo precisa mobilizar as instituições formadoras e de serviço para sua superação, o que requer a compreensão do cuidado de enfermagem em suas múltiplas dimensões - cuidar, gerenciar e educar, sem que uma seja valorativamente superior à outra.

Outra lacuna importanteque se identifica na função da enfermeira está na dimensão educativa, tanto no que se refere à educação para a saúde, voltada aos usuários, quanto à educação continuada, voltada aos trabalhadores. A dimensão educativa, frequentemente, é negligenciada tanto no mundo do trabalho quanto no mundo da formação. O que tem levado as enfermeiras a se distanciarem desse papel deeducadoras? Há um espaço educativo a ser preenchido pela enfermeira, compartilhado com os trabalhadores de enfermagem, e que se constitui numa poderosa estratégia de promoção da saúde e melhoria do processo de viver dos sujeitos.

Acreditamos que também a educação, quer dos trabalhadores, quer dos usuários, possibilitará o reconhecimento do papel social da enfermeira. Se não somos diferenciados pelo fazer junto ao cuidado direto, se o gerenciamento do cuidado é trabalho invisível e pouco reconhecido pela população, é pela via da educação que a enfermeira pode fazer a diferença na qualidade do cuidado prestado aos sujeitos, tornando-se a mola propulsora do reconhecimento e valorização profissional. Esse é um grande desafio, já que, na prática hospitalar, a enfermeira não tem conseguido garantir sua autonomia, pois suas ações e decisões situam-se entre a autoridade da administração superior e a autoridade técnica do médico, que ainda possui uma autonomia significativa em relação aos demais profissionais da área da saúde ${ }^{(13)}$.

A enfermagem deve pensar nos processos educativos não como mera reprodução do conhecimento/transmissão de informações, mas como um processo de emancipação dos sujeitos envolvidos - profissionais e usuários. Para tal, as enfermeiras precisam assumir o grande desafio de definir em que referencial pedagógico se fundará a dimensão educativa de seu processo de trabalho. Isso implica, também, em reconhecer os âmbitos político e ético do cuidado de enfermagem, e a partir daí reconhecer a importância da formação do enfermeiro no estudo das humanidades, uma formação humanística, que se contraponha à mera operacionalidade e que dá sentido existencial ao cuidar ${ }^{(14)}$. Como afirmam Assmann e Sung ${ }^{(15)}$, "a educação se transformou na tarefa emancipatória mais significativa". Para que isso se concretize, necessitamos atuar de maneira a integrar a competência profissional à competência social, em que a sensibilidade social e a sensibilidade ética estejam presentes para a construção de um mundo onde caibam todos. Para isso, precisamos ensinar a pensar, a cultivar o pensar complexo, de ordem superior, ensinando os aspectos genéricos do pensamento da disciplina, os aspectos inerentes a sua metodologia, bem como estimular o pensamento interdisciplinar, já que seu campo de atuação é compartilhado e requer o reconhecimento das linhas divisórias e os espaços intercessores entre as disciplinas, favorecendo a formação de profissionais críticoscriativos $^{(16)}$.

Oque tem ocorrido éque, na maioria das vezes, a enfermeira senta ao lado do usuário (quando senta!) e se limita a repassar informações de modo hierárquico e unilateral, sem muitas vezes ouvi-lo. Falamos muito e escutamos pouco. Énessa perspectiva de educação (ou seria adestramento?) que a enfermagem acredita? É possível que essa postura esteja fortemente relacionada com as próprias experiências 
de formação (e na pouca reflexão acerca dos fundamentos filosóficos da educação), que é compartimentada em matérias, impedindo a possibilidade de o trabalhador estabelecer o vínculo entre as partes e o todo, o corpo e o espírito, o objetivo e o subjetivo. O desafio da enfermagem é, portanto, superar tais insuficiências e estabelecer um "modo de conhecimento capaz de apreender os objetos em seu contexto, sua complexidade, seu conjunto, [...] estabelecer relações mútuas e as influências recíprocas entre as partes e o todo em um mundo complexo" ${ }^{\prime \prime 17: 14)}$, tanto nos processos de formação (inicial ou permanente) quanto nos processos de educação para a saúde.

A enfermagem é uma profissão que trabalha com o ser humano em sua complexidade e multidimensionalidade, e, por isso, precisa atentar-se à fragmentação do ser humano imposta pelo processo educativo e assistencial, criando alternativas pedagógicas que contribuam para reconstruir a complexa identidade humana. Acreditamos que cabe à enfermagem tomar a educação como princípio da esperança e como possibilidade de transformação dos cenários de cuidado à saúde, como já sugeriu Freire ${ }^{(18)}$.

\section{CONSIDERAÇÕES FINAIS}

A integralidade entendida como uma dimensão das práticas em saúde exige uma reflexão sobre as relações que se estabelecem entre os profissionais e os usuários e entre os próprios profissionais e uma ação para suplantar as relações conflituosas e de poder, estabelecendo uma prática pautada na interdisciplinaridade.
A abertura de espaços para a reorganização dos serviços de saúde, com vistas ao alcance da integralidade do cuidado, precisa incluir a reflexão do cotidiano de trabalho no processo deaprender a integralidade. Isso porque acreditamos que o cuidado requer uma ausculta sensível (na relação professor-aluno, na relação enfermeira-equipe de enfermagem, na relação enfermeira-equipe multiprofissional, na relação enfermeira-sujeito do cuidado), considerando o outro em sua multidimensionalidade.

Garantir a integralidade do cuidado requer ações de diferentes naturezas, desde a formação profissional até a mudança das práticas em saúde e enfermagem. Implica a mudança dos processos formativos dos profissionais de saúde, com a adoção de novas metodologias de ensino, bem como a formação pedagógica dos docentes em saúde; a integração dos diferentes serviços que compõem o sistema de saúde, bem como a efetiva integração ensino-serviço; o rompimento com a fragmentação do sujeito do cuidado e a valorização excessiva do biológico, do objetivo, reconhecendo a subjetividade (e seus efeitos) no processo de viver e adoecer. Isso porque "integralidade implica uma recusa ao reducionismo, uma recusa à objetivação dos sujeitos e talvez uma afirmação da abertura para o diálogo"(19:19).

Por fim, a reconstrução da práxis da enfermeira em busca da integralidade do cuidado requer a articulação, tanto na formação quanto no cotidiano da prática profissional, das dimensões de seu processo de trabalho: cuidar, gerenciar e educar.

\section{Referências}

1. Sawaia BB. A falsa cisão retalhadora do homem. In: Martinelli ML, Muchail ST, organizadores. O uno e o múltiplo: representação e cotidiano. São Paulo: Cortez; 1995. p. 84-122.

2. Merhy EE. Em busca do tempo perdido: a micropolítica do trabalho vivo em saúde. In: Merhy EE, Onocko R, organizadores. Praxis en salud: un desafio para lo público. Buenos Aires: Lugar Editorial/São Paulo: Hucitec; 1997.

3. Machado MFAS. Integralidade, formação de saúde, educação em saúde e as propostas do SUS - uma revisão conceitual. Ciênc Saúde Coletiva. 2007;12(2):335-42. 4. Merhy EE. Saúde: a cartografia do trabalho vivo. São Paulo: Hucitec; 2002. 5. Cecílio LC, Merhy EE. A integralidade do cuidado como eixo da gestão hospitalar [Internet]. [citado em 2006 Jan 25]. Disponível em: http:www.hc.ufmg. br/gids/Integralidade.doc.

6. Merhy EE, Cecílio LC. Algumas reflexões sobre o singular processo de coordenação dos hospitais. Saúde Debate. 2002.

7. Hausmann M, Peduzzi M. Articulação entre as dimensões gerencial e assistencial do processo de trabalho do enfermeiro. Texto Contexto Enferm. 2009; 18(2):258-65.

8. Beck CLC. Da banalização do sofrimento à sua ressignificação ética na organização do trabalho [tese]. Florianópolis: Universidade Federal de Santa Catarina; 2001. 9. Matos E. Novas formas de organização do trabalho e aplicação em enfermagem: limites e possibilidades [dissertação]. Florianópolis: Universidade Federal de Santa Catarina; 2002.

10. Mesquita MPL. A dimensão gerencial da identidade profissional da(o) enfermeira(o) na percepção da equipe de enfermagem: uma perspectiva de construção coletiva [dissertação]. Florianópolis: Universidade Federal de Santa Catarina; 2002.

11. Urbanetto J. Relações interpessoais e grupais no processo de trabalho das enfermeiras: convergências encontradas em dois hospitais universitários [tese]. Florianópolis: Universidade Federal de Santa Catarina; 2002.

12. Bueno AA, Bernardes $A$. Percepção da equipe de enfermagem de um serviço de atendimento pré-hospitalar móvel sobre o gerenciamento de Enfermagem. Texto Contexto Enferm. 2010;19(1):45-53.

13. Castrillón MC. La dimensión social de la práctica de la enfermería. Medellín: Editorial Universidad de Antioquia; 1997.

14. Souza ML, Sartor VVB, Padilha MICS, Prado ML. O cuidado de enfermagem uma aproximação teórica. Texto Contexto Enferm. 2005;14(2):266-70.

15. Assmann H, Sung JM. Competência e sensibilidade solidária: educar para a esperança. Petrópolis: Vozes; 2000.

16. Reibnitz KS, Prado ML. Formação do profissional crítico-criativo: a investigação como atitude de (re)conhecimento do mundo. Texto Contexto Enferm. 2003;12(1):26-33.

17. Morin E. Os sete saberes necessários à educação do futuro. $2^{\mathrm{a}}$ ed. São Paulo: Cortez/Brasília: Unesco; 2000.

18. Freire P. Pedagogia da esperança: um reencontro com a pedagogia do oprimido. $5^{\text {a }}$ ed. Rio de Janeiro: Paz e Terra; 1998.

19. Mattos RA. Os sentidos da integralidade: algumas reflexões acerca de valores que merecem ser defendidos. In: Pinheiro R, Mattos RA. Os sentidos da integralidade na atenção e no cuidado à saúde. Rio de Janeiro: Uerj; 2001. p. 39-64. 